\title{
A EVOLUÇÃO COMO EIXO INTEGRADOR DAS CIÊNCIAS BIOLÓGICAS: UMA UNIDADE DIDÁTICA NO CONTEXTO DO ENSINO DE BIOLOGIA
}

\author{
EVOLUTION AS A UNIFYING AXIS OF BIOLOGICAL SCIENCES: A \\ TEACHING UNIT IN THE CONTEXT OF BIOLOGY TEACHING
}

\author{
Pedro Leonardo Guarilha Colli ${ }^{1}$ \\ Mariana A. Bologna Soares de Andrade ${ }^{2}$ \\ Vinícius Colussi Bastos ${ }^{3}$
}

\begin{abstract}
Resumo: Estudos realizados nas últimas décadas indicam que a Biologia vem sendo ensinada de forma fragmentada e descontextualizada nas escolas brasileiras. Dentre os fatores apontados como causa desta tendência, destaca-se a negligência em relação ao ensino de Evolução, que raramente é tratado como o eixo integrador das Ciências Biológicas. Partindo disso, este estudo propõe uma Unidade de Ensino Potencialmente Significativa (UEPS) para a promoção da aprendizagem das ideias fundamentais à formação do pensamento evolutivo e compreensão dos fenômenos e mecanismos biológicos de maneira integrada e contextualizada. A UEPS construída aborda a Evolução por meio das cinco principais ideias evolucionistas do paradigma darwiniano e é sugerida para ser utilizada no primeiro ano do Ensino Médio.
\end{abstract}

Palavras-chave: Ensino de Evolução; Didática da Biologia; Aprendizagem Significativa; UEPS.

\begin{abstract}
Studies carried out in the last decades indicate that Biology has been taught in a fragmented and decontextualized way in Brazilian schools. Among the factors pointed out as the cause of this trend, the negligence related to the teaching of Evolution stands out, which is rarely treated as the unifying axis of the Biological Sciences. Based on these understandings, this study proposes a Potentially Meaningful Teaching Unit (PMTU) to promote the learning of fundamental ideas for the formation of evolutionary thinking and understanding of biological phenomena and mechanisms in an integrated and contextualized way. The PMTU developed addresses Evolution through the five main evolutionary ideas of the Darwinian paradigm and is suggested to be used in the first year of High School.
\end{abstract}

Keywords: Teaching of Evolution; Biology Teaching; Meaningful Learning; PMTU.

1 Introdução

A Biologia, como ciência responsável pelo estudo das mais diversas formas de vida, é relativamente jovem. Sua criação, por meio da junção de várias outras áreas de

\footnotetext{
${ }^{1}$ Mestrando em Ensino de Ciências e Educação Matemática (UEL). Universidade Estadual de Londrina (UEL), Londrina, Paraná, Brasil. E-mail: pedrolgcolli@ hotmail.com

${ }^{2}$ Doutora em Educação Para a Ciência (UNESP). Universidade Estadual de Londrina (UEL), Londrina, Paraná, Brasil. E-mail: mariana.bologna@gmail.com

${ }^{3}$ Doutor em Ensino de Ciências e Educação Matemática (UEL). Universidade Estadual de Londrina (UEL), Londrina, Paraná, Brasil. E-mail: colussi.bastos@gmail.com
} 
DOI: https://doi.org/10.33238/ReBECEM.2021.v.5.n.1.26905

estudos que até então não se integravam, como a Botânica, a Zoologia e a Anatomia, ocorreu principalmente respaldada no evolucionismo. Isso significa, então, que o pensamento evolutivo é o eixo integrador e o fator que confere sentido à Biologia (MEYER; EL-HANI, 2005). Esta concepção, como afirmam Diogo Meyer e Charbel ElHani $(2005)^{4}$, é endossada pela maioria dos estudiosos da Biologia:

\begin{abstract}
A maior parte da comunidade científica considera o pensamento evolutivo o eixo central e unificador das Ciências Biológicas. A evolução é tipicamente entendida como um elemento indispensável para a compreensão apropriada da grande maioria dos conceitos e das teorias encontrados nessas ciências (MEYER; EL-HANI, 2005, p. 123).
\end{abstract}

Partindo desse princípio, considera-se que o ensino de Biologia nas escolas deve ocorrer de modo a promover o desenvolvimento de uma compreensão integrada dessa ciência por parte dos alunos. Neste contexto, o papel do professor é ensinar os conteúdos estruturantes de maneira contextualizada e destacando a interação que existe entre eles, que é explicada somente por meio de uma visão evolucionista do fenômeno vida (MEYER; EL-HANI, 2005).

Além disso, entende-se que o ensino de Biologia deve ser abordado sob uma perspectiva crítica de educação, isto é, deve fugir da concepção conteudista de ensino, que privilegia a transmissão de conhecimento em oposição à construção deste com a participação ativa do aprendiz. Uma perspectiva que se pode pensar também junto com Paulo Freire, em suas palavras: "ensinar não é transferir a inteligência do objeto ao educando, mas instigá-lo no sentido de que, como sujeito cognoscente, se torne capaz de inteligir e comunicar o inteligido" (2018, p. 117).

Em contrapartida, o ensino de Biologia tradicional é indicado por estudos da área ao longo das últimas duas décadas como a abordagem mais empregada, caracterizandose pela maneira fragmentada e descontextualizada dos conteúdos, o que favorece o ensino conteudista e a aprendizagem pela memorização sem compreensão. Um dos motivos apontados como responsáveis por este fenômeno é o fato de a Evolução Biológica, considerada a ideia integradora para toda a Biologia, ter seu ensino muitas vezes negligenciado pelos professores da disciplina. Isso se deve a diferentes fatores, como a falta de formação dos docentes para o tratamento do assunto, a tentativa de evitar conflitos morais e religiosos gerados com o tema e até mesmo a forma inadequada como a

\footnotetext{
${ }^{4}$ Optamos, neste trabalho, por utilizar o primeiro nome e o sobrenome dos autores quando mencionados pela primeira vez no texto. O objetivo desta prática é evidenciar o gênero dos autores e, assim, dar mais visibilidade às contribuições das mulheres para a pesquisa.
} 
DOI: https://doi.org/10.33238/ReBECEM.2021.v.5.n.1.26905

Evolução Biológica é apresentada nos livros didáticos, que frequentemente apoiam e orientam os professores em sala de aula (OLEQUES et al., 2011; ZAMBERLAN; SILVA, 2012).

Neste contexto, levanta-se o seguinte problema: como promover o ensino de Evolução Biológica (EB) na Educação Básica, para uma aprendizagem significativa e crítica, a fim de exercer o papel de eixo integrador dos conteúdos de Biologia? Com isso, este trabalho propõe como objetivo geral um estudo teórico e a apresentação de uma Unidade de Ensino Potencialmente Significativa (UEPS) que promova a aprendizagem significativa e crítica dos conceitos e ideias essenciais que regem o fenômeno evolutivo para que estes, por sua vez, possivelmente desempenhem o papel de subsunçores de outros conceitos, processos e fenômenos da Biologia. Isto é, o ensino de Evolução Biológica como eixo centralizador e unificador das Ciências Biológicas. Já seus objetivos específicos foram: analisar e definir estratégias didáticas a serem utilizadas em uma UEPS a fim de promover a formação de organizadores prévios que proporcionam a compreensão da EB como eixo integrador da Biologia; organizar a sequência mais apropriada de conteúdos a serem abordados na proposta; selecionar ferramentas e materiais de apoio que podem ser empregados nas aulas.

Evidencia-se que este foi um estudo teórico, pautado na articulação de contribuições da Didática da Biologia, da Aprendizagem Significativa Crítica e da Epistemologia da Biologia, que buscou construir uma ferramenta que seja capaz de amparar e conduzir as reflexões do educador de Biologia para trabalhar o ensino de EB de maneira que este fundamente e integre os conteúdos das Ciências Biológicas ensinados na Educação Básica.

\section{A Evolução Biológica como eixo integrador e a Aprendizagem Significativa Crítica}

A Biologia é a ciência que tem como objetivo o estudo dos seres vivos, suas características e interações. Desta maneira, considera-se importante que na disciplina de Biologia os alunos compreendam o fenômeno vida e toda sua complexidade de relações sob uma perspectiva científica (PARANÁ, 2008).

Apesar de parecer natural que haja uma ciência que se encarregue do estudo dos seres vivos e suas características, ela não existia até o século XVIII. Segundo Meyer e ElHani (2005), até essa época animais, plantas, seres humanos, etc. eram estudados 
DOI: https://doi.org/10.33238/ReBECEM.2021.v.5.n.1.26905

separadamente e esses estudos não se integravam. Ainda de acordo com os autores, a Biologia como ciência unificada, voltada ao estudo de todos os seres vivos, surgiu apenas no século seguinte e foi concebida por pensadores evolucionistas. Desta forma, como defendem Meyer e El-Hani (2005), a Biologia já teria nascido sob uma ótica evolucionista. Isso, porque somente a partir do entendimento de que todas as formas vivas existentes no planeta são aparentadas entre si, ou seja, que possuem um ancestral em comum, faria sentido estudá-las de forma integrada e sob um único conjunto de princípios. Esse pensamento é bem representado pela famosa frase de Theodosius Dobzhansky, proferida em um artigo do ano de 1973: "Nada faz sentido em Biologia se não for à luz da evolução" (p. 125).

As Diretrizes Curriculares da Educação Básica do Estado do Paraná (PARANÁ, $2008)^{5}$, documento que norteou por mais de dez anos a elaboração dos currículos neste Estado e que permaneceu vigente até 2019, ano de elaboração deste estudo, sugerem que o ensino de Biologia seja trabalhado nas escolas com base em quatro conteúdos estruturantes que representam os paradigmas históricos e filosóficos das Ciências Biológicas. Esses quatro eixos que dão base ao currículo de Biologia são: Organização dos Seres Vivos; Mecanismos Biológicos; Biodiversidade; Manipulação Genética. Apesar de organizar o ensino da disciplina sob esses diferentes enfoques, o documento também salienta que eles são interdependentes e que "em sua abordagem teóricometodológica, eles devem considerar as relações que estabelecem entre si e entre os conteúdos tratados no dia-a-dia da sala de aula [...]" (PARANÁ, 2008, p. 55). Isto é, o ensino de Biologia, sob a orientação desses quatro conteúdos estruturantes, precisa não somente estar contextualizado com a realidade dos estudantes, como também precisa se dar de forma a evidenciar, sempre que possível, de que maneira tais conteúdos se interrelacionam (PARANÁ, 2008).

A Base Nacional Comum Curricular (BNCC) (BRASIL, 2017), documento que atualmente orienta a estruturação dos currículos na educação básica em todos os estados brasileiros, não sugere de forma clara que a Evolução seja ensinada como eixo integrador das Ciências Biológicas. A BNCC, no entanto, dá destaque à importância da origem, evolução e manutenção da vida no ensino das Ciências da Natureza e suas Tecnologias -

\footnotetext{
${ }^{5}$ A partir da implementação da BNCC, o Estado do Paraná criou, de forma complementar, o Referencial Curricular do Paraná (PARANÁ, 2018) com a finalidade de substituir as Diretrizes Curriculares da Educação Básica do Estado do Paraná. No entanto, até o momento de produção deste artigo o novo documento ainda não contempla o Ensino Médio e, por isso, as diretrizes de 2008 permanecem influenciando os currículos nessa etapa da educação básica.
} 
DOI: https://doi.org/10.33238/ReBECEM.2021.v.5.n.1.26905

que abrange as disciplinas de Biologia, Física e Química - para a formação cidadã do aprendiz. Ainda de acordo com o documento, o processo de ensino e aprendizagem deve ocorrer de maneira contextualizada e voltado ao desenvolvimento de determinadas competências pelos estudantes (BRASIL, 2017). Conforme a Competência Específica 2, que está diretamente relacionada ao ensino de Evolução, o educando deve ser capaz de

[...] construir e utilizar interpretações sobre a dinâmica da Vida, da Terra e do Cosmos para elaborar argumentos, realizar previsões sobre o funcionamento e a evolução dos seres vivos e do Universo, e fundamentar decisões éticas e responsáveis (BRASIL, 2017, p. 539).

Concernentes às competências, a BNCC também define algumas habilidades a serem alcançadas pelos aprendizes. Entre elas, algumas são mais proximamente vinculadas ao ensino de Biologia e de Evolução, como:

(EM13CNT201) Analisar e utilizar modelos científicos, propostos em diferentes épocas e culturas para avaliar distintas explicações sobre o surgimento e a evolução da Vida, da Terra e do Universo.

(EM13CNT202) Interpretar formas de manifestação da vida, considerando seus diferentes níveis de organização (da composição molecular à biosfera), bem como as condições ambientais favoráveis e os fatores limitantes a elas, tanto na Terra quanto em outros planetas.

(EM13CNT203) Avaliar e prever efeitos de intervenções nos ecossistemas, nos seres vivos e no corpo humano, interpretando os mecanismos de manutenção da vida com base nos ciclos da matéria e nas transformações e transferências de energia.

(EM13CNT206) Justificar a importância da preservação e conservação da biodiversidade, considerando parâmetros qualitativos e quantitativos, e avaliar os efeitos da ação humana e das políticas ambientais para a garantia da sustentabilidade do planeta.

(EM13CNT207) Identificar e analisar vulnerabilidades vinculadas aos desafios contemporâneos aos quais as juventudes estão expostas, considerando as dimensões física, psicoemocional e social, a fim de desenvolver e divulgar ações de prevenção e de promoção da saúde e do bem-estar (BRASIL, 2017, p. 543).

Apesar de a BNCC não fazer menção explícita à EB como eixo centralizador e unificador das Ciências Biológicas, entende-se aqui, com base no que é defendido por Meyer e El-Hani (2005), Mayr (2005; 2009) e Paraná (2008), que o desenvolvimento das habilidades pretendido pelo documento norteador poderia ser facilitado caso as Ciências da Natureza fossem ensinadas sob uma perspectiva evolucionista, de forma que a Evolução permeasse e fundamentasse a compreensão dos fenômenos naturais relacionados à vida na Terra. 
DOI: https://doi.org/10.33238/ReBECEM.2021.v.5.n.1.26905

Como já mencionado anteriormente, para autores como Dobzhansky (1973) e Meyer e El-Hani (2005) é a concepção evolucionista que dá sentido à Biologia, de modo que "pensar biologicamente é pensar evolutivamente" (MEYER; EL-HANI, 2005, p. 114). Outro estudioso da Biologia que compartilha deste pensamento é Ernst Mayr. Nas palavras do autor:

\begin{abstract}
A evolução é o conceito mais importante da biologia. Não há uma única pergunta "Por quê?" em biologia a que se possa responder de maneira adequada sem levar em conta a evolução. Entretanto, a importância deste conceito vai muito além da biologia. O pensamento do homem moderno, quer percebamos isso ou não, é profundamente afetado - quase se tem a tentação de dizer determinado - pelo pensamento evolucionista (MAYR, 2009, p. 15).
\end{abstract}

Mayr (2005; 2009) também diz que a Biologia moderna se apoia fundamentalmente na teoria evolucionista desenvolvida por Darwin. Segundo ele, o pensamento evolutivo darwinista é, na realidade, constituído por cinco teorias distintas, descritas a seguir:

1) a "evolução propriamente dita" diz respeito ao fato, amplamente constatado e documentado, de que as espécies são mutáveis, ou seja, de que as populações de organismos passam por transformações ao longo do tempo. Essa teoria se opõe à ideia fixista, segundo a qual as espécies permaneceriam sempre inalteradas;

2) a "descendência comum" é a ideia de que todas as espécies existentes, e as já extintas, descenderam de um ancestral em comum. Essa foi a teoria darwinista inicialmente melhor aceita pela comunidade científica da época e os avanços recentes no entendimento dos fenômenos e mecanismos biológicos apenas a reforçaram. Atualmente, é virtualmente unânime entre os estudiosos das áreas biológicas que todos os seres vivos da Terra descenderam de uma única origem da vida;

3) o "gradualismo" é o princípio conforme o qual a Evolução ocorre, sobretudo, de maneira gradual. Isto é, ela ocorre por meio do acúmulo gradual de pequenas alterações nas características dos indivíduos de uma população ao longo de várias gerações. Esta teoria evidencia o pensamento populacional inerente à concepção evolucionista de Darwin que hoje, segundo Mayr (2009), é considerado consenso. Nas palavras do autor, "Evolução é a mudança das propriedades de populações de organismos ao longo do tempo" (MAYR, 2009, p. 28);

4) a "multiplicação das espécies" é a teoria que aborda a tendência das espécies a se multiplicarem e busca explicar os mecanismos e fenômenos determinantemente envolvidos no surgimento de toda a diversidade de seres vivos que habitam ou já 


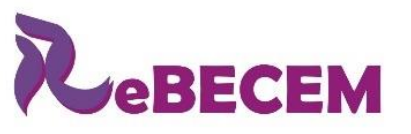

Revista Brasileira de Educação em

Ciências e Educação Matemática

ISSN 2594-9179

DOI: https://doi.org/10.33238/ReBECEM.2021.v.5.n.1.26905

habitaram o planeta. De acordo com Mayr (2005; 2009), Darwin não conseguiu oferecer uma solução convincente em relação ao fenômeno da especiação à sua época, mas já tinha noção dos dois principais processos pelos quais as espécies se multiplicam, o alopátrico - quando há isolamento geográfico - e o simpátrico - quando não há a necessidade de um isolamento geográfico para que uma nova espécie se origine;

5) a "seleção natural" refere-se à ideia de que os indivíduos de uma espécie estão sempre sujeitos a serem naturalmente selecionados ou eliminados. Segundo Mayr (2005; 2009), a teoria, desenvolvida independentemente por Darwin e Wallace, funciona em duas etapas: os indivíduos de uma população produzem variações aleatórias de características e essas variações são discriminadas por seleção e eliminação, favorecendo aqueles indivíduos cujas variedades fenotípicas são mais vantajosas. Assim, "os indivíduos mais bem preparados para enfrentar os desafios do ambiente e competir com outros membros da sua população têm maior probabilidade de sobreviver até a idade fértil e de se reproduzir com sucesso" (MAYR, 2009, p. 149). A seleção natural é, portanto, considerada o principal mecanismo por meio do qual a Evolução Biológica ocorre. Com isso, essas teorias, que podem ser entendidas também como princípios ou ideias, constituem a base para a compreensão das ideias de Darwin e, consequentemente, da Biologia Evolutiva (MAYR, 2005; 2009).

Em conformidade com essa perspectiva e com base na essencialidade de que o ensino de Biologia ocorra de forma integrada, propõe-se que

[...] o pensamento evolutivo é o eixo organizador do conhecimento biológico. É ele que confere sentido à diversidade de ramos do conhecimento que constituem a Biologia. Evolução não é somente mais um conteúdo de Biologia, mas também é o conteúdo mais central de toda essa ciência, sem o qual ela simplesmente não tem sentido (MEYER; EL-HANI, 2005, p.114).

Logo, não se pode tratar o ensino de EB da mesma forma que comumente se trata os outros conteúdos ensinados em Biologia. Isso, porque a Evolução tem papel central e função integradora nas Ciências Biológicas e, consequentemente, também no ensino desta disciplina nas escolas (MEYER; EL-HANI, 2005).

Segundo Luciane Oleques et al. (2011), ainda que não se possa negar a importância do ensino de Evolução Biológica para a compreensão do fenômeno vida, esse é um tema que costuma gerar conflitos morais, principalmente por ir de encontro às crenças religiosas de muitas pessoas. Tal fato, por si só, já explicaria o porquê de alguns professores evitarem dar o destaque que o tema merece, relegando-o muitas vezes ao último ano do Ensino Médio e abordando-o de forma isolada e descontextualizada. 
DOI: https://doi.org/10.33238/ReBECEM 2021.v.5.n.1.26905

Contudo, além da polêmica, outras dificuldades são apresentadas para justificar a pouca relevância que o ensino de EB recebe nas aulas de Biologia, como a falta de tempo, a má organização curricular e a falta de preparo dos professores em virtude de uma formação inadequada.

Os trabalhos de Rosana Tidon e Richard Lewontin (2004) e Oleques et al. (2011) demonstram uma tendência dos professores de Biologia a trabalharem o tema Evolução em poucas aulas e somente ao final do ano letivo. Essa prática, segundo os autores, prioriza um ensino fragmentado da Biologia que, sem o enfoque evolutivo, que é o eixo integrador dessa ciência, se torna um ensino conteudista e memorístico. Essa organização curricular e ação docente, característicos de um ensino de Biologia tradicional, que prioriza a transmissão de conhecimentos do professor para o aluno, geram percalços à efetivação do trabalho pedagógico aqui defendido, destoando também das orientações de documentos oficiais, como as Diretrizes Curriculares da Educação Básica do Paraná (PARANÁ, 2008).

Vale destacar também que, de acordo com Meyer e El-Hani (2005), para que haja qualidade na educação científica a aprendizagem das ciências, e aqui inclui-se a Biologia, precisa ser acompanhada de uma aprendizagem sobre as ciências, ou seja, sobre a filosofia e a história da ciência. Isso permite que o estudante compreenda como o conhecimento científico foi e continua sendo construído ao longo da história e suas implicações filosóficas e sociais.

Diante das transformações sociais dos últimos sessenta anos, que fizeram avanços científicos e tecnológicos influenciarem de uma maneira sem precedentes as estruturas sociais, a cultura e a vida cotidiana, o Ensino de Ciências não pode mais retratar a prática científica como se fosse separada da sociedade, da cultura e da vida cotidiana, e como se não possuísse uma dimensão histórica e filosófica (MEYER; EL-HANI, 2005, p. 10).

Para Freire (2018), ensinar exige criticidade, isto é, exige o desenvolvimento da capacidade crítica do aprendiz. No entanto, não se deve buscar estabelecer uma ruptura entre a curiosidade ingênua do estudante e a curiosidade crítica pretendida pelo professor. O que se deve buscar, então, é manter a curiosidade viva no aluno ao mesmo tempo em que se promove uma superação desta curiosidade ingênua no sentido da criticidade. Segundo o autor, para que se estabeleça uma aprendizagem crítica é necessário que o educador, durante suas aulas, utilize meios que permitam que os alunos participem ativamente do processo de ensino e aprendizagem, uma vez que "ensinar não é transferir conhecimento, mas criar as possibilidades para a sua própria produção ou a sua 
DOI: https://doi.org/10.33238/ReBECEM.2021.v.5.n.1.26905 construção" (FREIRE, 2018, p. 47).

De acordo com Marco Moreira (2010), a aprendizagem mecânica é aquela que não exige criticidade dos estudantes, pois eles não precisam pensar sobre aquilo que estão aprendendo, eles apenas memorizam as informações recebidas e depois as repetem nas avaliações. O autor também sugere que, ao contrário do que ocorre na aprendizagem mecânica, na aprendizagem significativa o aluno não é um receptor passivo. Neste tipo de aprendizagem o aluno é um agente ativo na construção/produção do próprio conhecimento. Desta maneira, a aprendizagem significativa, que foi descrita inicialmente por David Ausubel, é uma aprendizagem com significado, com sentido e que envolve a compreensão crítica do aluno (MOREIRA, 2010).

Para que ela ocorra, o estudante precisa manifestar predisposição para aprender significativamente aquilo que se pretende ensinar, este novo conhecimento precisa ser relevante e precisa ser percebido como tal pelo aprendiz e, não menos importante, o novo conhecimento precisa ser relacionado a algum conhecimento pré-existente na estrutura cognitiva de quem se dispõe a aprendê-lo. "A aprendizagem significativa caracteriza-se pela interação cognitiva entre o novo conhecimento e o conhecimento prévio" (MOREIRA, 2010, p. 4). Em outras palavras, um novo conceito, para que possa ser significativamente aprendido, precisa ancorar-se em algo que o estudante já saiba. Este conhecimento prévio é também chamado de subsunçor (MOREIRA, 2012).

No entanto, Moreira (2012) chama a atenção para a possibilidade de os estudantes não possuírem os conhecimentos prévios necessários para a efetiva assimilação dos conceitos a serem ensinados. Neste caso, o autor, alicerçado nas ideias propostas por Ausubel, sugere a utilização de materiais que sirvam como "ancoradouro provisório" ou "pontes cognitivas" entre o que o aluno já sabe e aquilo que almeja aprender. Ainda de acordo com Moreira (2012), esses materiais introdutórios, chamados de organizadores prévios, devem ser apresentados antes do material de aprendizagem em si e devem ser mais gerais e inclusivos do que o material que será proposto na sequência.

Entretanto, segundo Moreira (2010), a aprendizagem significativa de um novo conhecimento não é suficiente quando se propõe formar cidadãos aptos a intervir no mundo e provocar as mudanças necessárias nas estruturas da sociedade. Para este fim, o autor sugere uma aprendizagem significativa subversiva, ou crítica como, ele prefere chamar. 
DOI: https://doi.org/10.33238/ReBECEM.2021.v.5.n.1.26905

mitos e ideologias. É através dessa aprendizagem que ele poderá lidar construtivamente com a mudança sem deixar-se dominar por ela, manejar a informação sem sentir-se impotente frente a sua grande disponibilidade e velocidade de fluxo, usufruir e desenvolver a tecnologia sem tornar-se tecnófilo. Por meio dela, poderá trabalhar com a incerteza, a relatividade, a não-causalidade, a probabilidade, a não-dicotomização das diferenças, com a ideia de que o conhecimento é construção (ou invenção) nossa, que apenas representamos o mundo e nunca o captamos diretamente (MOREIRA, 2010, p. 7).

Contudo, com base no que é postulado por Moreira (2010), Freire (2018) e Meyer e El-Hani (2005), entende-se que é imprescindível que o ensino das ciências, com destaque para a Biologia, seja praticado de maneira crítica nas escolas, a fim de promover uma aprendizagem com significados que se conectam com os modos de vida dos alunos para uma tomada fundamentada de decisões. E entende-se, também, que o ensino de Evolução Biológica, fundamentado nestes princípios, deva ser desenvolvido de forma a orientar e integrar o ensino de Biologia e seus conteúdos estruturantes.

\section{Procedimentos metodológicos}

Neste estudo propõe-se uma unidade didática que seja capaz de promover uma aprendizagem significativa e crítica dos conceitos fundamentais à formação de subsunçores para a compreensão do fenômeno evolutivo como eixo integrador das Ciências Biológicas. Para este fim, foi escolhida a abordagem de uma pesquisa bibliográfica (FONSECA, 2002), que se caracteriza como um procedimento teórico de análise de material já elaborado (GIL, 2008). Assim, no processo desenvolvido neste trabalho foi analisado material teórico relacionado à evolução biológica e fundamentos da aprendizagem significativa crítica buscando a articulação para a elaboração e discussão de uma unidade didática.

Portanto, com base nos objetivos desta investigação, principalmente no que tange ao desenvolvimento de uma unidade didática que possibilite uma aprendizagem significativa e crítica, optou-se pela estrutura idealizada por Moreira (2012) e intitulada de Unidade de Ensino Potencialmente Significativa (UEPS). Segundo o autor, as UEPS "são sequências de ensino fundamentadas teoricamente, voltadas para a aprendizagem significativa, não mecânica, que podem estimular a pesquisa aplicada em ensino, aquela voltada diretamente à sala de aula" (MOREIRA,2012, p. 2).

Com o propósito de estruturar a construção de uma UEPS, Moreira (2012) sugere 
DOI: https://doi.org/10.33238/ReBECEM.2021.v.5.n.1.26905

oito passos, ou aspectos sequenciais. Estes, no entanto, não devem ser vistos como um receituário, uma vez que permitem adaptações, mas sim como uma ferramenta que possa orientar as ações de ensino no sentido da aprendizagem significativa.

1- Definição do tema;

2- Criação de situação que incentive o aluno a expor seus conhecimentos prévios;

3- Proposição das situações-problema em nível de complexidade coerente com os conhecimentos prévios dos estudantes. Segundo o autor, esta etapa serve para que se faça uma introdução ao tema, mas ainda sem ensiná-lo, com a finalidade de se estabelecer o que ele chama de organizador prévio, que fará a ponte entre o que o aprendiz já sabe e o que será ensinado;

4- Apresentação do conhecimento a ser ensinado/aprendido levando em conta o princípio da diferenciação progressiva, que determina que o novo conhecimento seja ensinado partindo de conceitos mais gerais e inclusivos e, ao longo do processo, evoluindo em direção a ideias mais detalhadas e específicas. Assim, neste momento é dada uma visão inicial e mais geral do novo conhecimento;

5- Retomada dos aspectos estruturantes do conteúdo que se pretende ensinar, mas em nível mais alto de complexidade, com novos exemplos e em novas situações, de forma a "[...] destacar semelhanças e diferenças relativamente às situações e exemplos já trabalhados, ou seja, promover a reconciliação integradora” (MOREIRA, 2012, p. 4);

6- Conclusão da unidade. Mais uma vez respeitando os princípios da diferenciação progressiva e reconciliação integradora, deve-se retomar os aspectos mais relevantes do conteúdo a ser ensinado/aprendido sob uma nova ótica, de forma integradora e em nível mais alto de complexidade;

7- Avaliação do aluno. De acordo com Moreira (2012), em uma UEPS a avaliação, que deve ser formativa, é necessariamente feita durante sua implementação e tudo que demonstre a ocorrência de aprendizagem significativa deve ser registrado. Porém, devese também ser proposta ao estudante uma avaliação individual e somativa por meio de atividades que possam evidenciar a assimilação de significados;

8- Avaliação da UEPS. Este último passo tem como objetivo avaliar a própria sequência didática e as estratégicas utilizadas pelo professor. E, nas palavras de Moreira (2012) “a UEPS somente será considerada exitosa se a avaliação do desempenho dos alunos fornecer evidências de aprendizagem significativa", ou seja, se ficar demonstrado que, além da captação e compreensão dos significados, os estudantes desenvolveram também a capacidade de explicação e de aplicação do que foi aprendido na resolução de 
problemas.

Fundamentando-se, então, nas ideias apresentadas sobre a Didática da Biologia, sobre o fenômeno evolutivo e nos princípios da Aprendizagem Significativa Crítica, construiu-se, conforme o modelo de UEPS sugerido por Moreira (2012), a unidade de ensino proposta neste estudo. É evidente que um processo de avaliação da UEPS construída seja relevante para validar a proposta, bem como possíveis aplicações em diferentes realidades escolares com a análise das aprendizagens potencialmente ocorridas ao longo do seu desenvolvimento. Contudo, esta pesquisa dedicou-se às articulações e contribuições teóricas necessárias às possíveis aplicações e análises.

\section{Uma UEPS para a compreensão dos princípios evolutivos}

Em conformidade com os objetivos previamente definidos, a Unidade de Ensino Potencialmente Significativa (UEPS) foi construída com o propósito de viabilizar a aprendizagem significativa e crítica dos princípios fundamentais do processo de Evolução Biológica de modo a permitir que os estudantes sejam capazes de desenvolver um pensamento evolutivo que servirá como ancoradouro para os conceitos que lhes serão apresentados durante o ensino de Biologia no decorrer do Ensino Médio (EM). Ou seja, o pensamento evolutivo como eixo organizador do conhecimento biológico, como defendido por Meyer e El-Hani (2005) e outros estudiosos das Ciências Biológicas e do seu ensino. Uma vez que o conhecimento que se pretende ensinar nesta unidade é considerado basilar para o aprendizado de diversos outros conceitos e fenômenos da Biologia, propõe-se que essa UEPS seja posta em prática ao início do ensino da referida disciplina, o que ocorre no $1^{\circ}$ ano do EM.

A seguir, é apresentada a UEPS proposta. Ela foi estruturada em seis passos ${ }^{6}$, orientados pelos aspectos sequenciais definidos por Moreira (2012) descritos anteriormente, e aqui foi organizada no Quadro 1 a fim de facilitar a identificação e a compreensão de cada uma das etapas. Após o quadro, cada passo foi explicado de modo a enfatizar seus elementos didáticos que contribuem para a consolidação de uma UEPS.

\footnotetext{
${ }^{6}$ A UEPS foi estruturada em seis passos e não em oito, como sugerem os aspectos sequenciais estabelecidos por Moreira (2012), pois alguns dos passos contemplam mais de um aspecto de maneira integrada. Essa flexibilidade dos aspectos sequenciais é salientada pelo próprio autor.
} 
DOI: https://doi.org/10.33238/ReBECEM.2021.v.5.n.1.26905

\begin{tabular}{|c|c|}
\hline $\begin{array}{l}\text { Passos da } \\
\text { Unidade }\end{array}$ & Atividades Propostas \\
\hline Passo 1 & $\begin{array}{l}\text { Conteúdo 1: A diversidade de seres vivos } \\
\text { Questionamento inicial: A pergunta "O que vocês entendem por diversidade de seres } \\
\text { vivos?" é feita em sala de aula a fim de levantar os conhecimentos e ideias prévias dos } \\
\text { alunos no que diz respeito à diversidade de seres vivos existentes na Terra. } \\
\text { Problematização: Em seguida, o docente pode lançar questionamentos, como: Quantas } \\
\text { espécies de seres vivos existem? Como ocorreu tamanha diversidade de (espécies) seres } \\
\text { vivos em nosso planeta? O que seres aparentemente tão diferentes, como animais, plantas, } \\
\text { fungos e bactérias, têm em comum? Tais questões têm como intuito fazer os alunos } \\
\text { pensarem, pesquisarem e debaterem o assunto em sala de aula. } \\
\text { Apresentação expositiva dialogada: Após ouvir e discutir as respostas dos estudantes às } \\
\text { questões anteriores, o professor, utilizando um projetor como recurso, exibe o vídeo "Bio } \\
\text { é vida diversidade de } \\
\text { (https://www.youtube.com/watch?v=mr45_Yu2xos\&t=321s) para introduzir o assunto e, } \\
\text { na sequência, apresenta uma imagem de árvore da vida, ou árvore filogenética } \\
\text { (https://evogeneao.s3.amazonaws.com/images/tree of life/tree-of-life 2000.png) } \\
\text { representando em suas ramificações todos os grupos de seres vivos existentes e como todos } \\
\text { partiram de um ancestral em comum. A partir do vídeo e da imagem apresentados, o } \\
\text { docente explica brevemente que todas as formas de vida que já existiram na Terra } \\
\text { descenderam de um ancestral em comum, ou seja, de uma forma de vida que surgiu há } \\
\text { bilhões de anos e que se diversificou com o passar do tempo, dando origem a todas as } \\
\text { formas de vida que conhecemos. } \\
\text { Tempo estimado: duas horas-aula. }\end{array}$ \\
\hline Passo 2 & 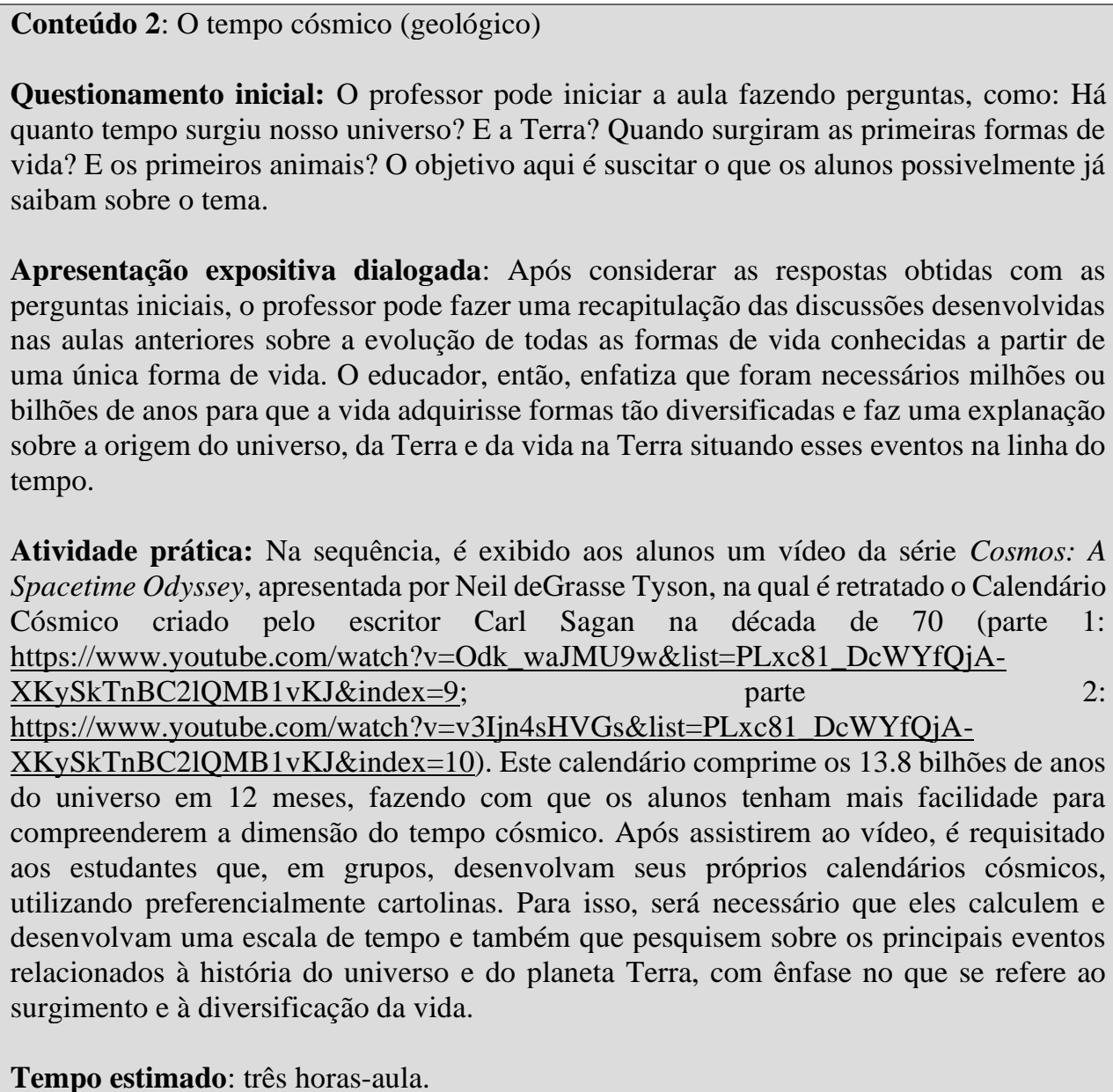 \\
\hline
\end{tabular}


DOI: https://doi.org/10.33238/ReBECEM.2021.v.5.n.1.26905

\section{Conteúdo 3: Evolução Biológica}

Problematização: O que é a Evolução Biológica? Como ela ocorre? Após iniciar a aulas fazendo esses questionamentos, o professor escuta e problematiza as respostas dadas pelos estudantes, a fim de gerar uma discussão e levantar mais questionamentos e os conhecimentos prévios dos alunos sobre o assunto.

Antes de qualquer explicação, o docente apresenta aos alunos o vídeo "Nós, os fantásticos seres vivos: uma breve história sobre Evolução"

Passo 3 (https://www.youtube.com/watch?v=pYbKhi5rqqs) e, ao final, refaz as perguntas feitas no início da aula adicionando uma terceira pergunta: Há relação entre a Evolução Biológica e a diversidade de seres vivos encontrada no planeta Terra? Se sim, qual?

Os alunos são orientados a formarem grupos para debaterem e, com base em seus conhecimentos prévios e no que foi aprendido nas primeiras aulas, apresentarem suas hipóteses respondendo ao último questionamento lançado pelo professor.

Tempo estimado: uma hora-aula.

Atividade prática: Propõe-se aos estudantes a atividade "Jogo da Evolução" (http://www.biologia.seed.pr.gov.br/arquivos/File/jogos/jogo_da_evolucao.pdf). O jogo, como o próprio nome sugere, tem como objetivo facilitar aos alunos o entendimento de como ocorre o processo da Evolução Biológica.

Passo 4

Antes do jogo, a turma é dividida em grupos, cada grupo recebe o material necessário e o docente explica suas regras e seu funcionamento. Após as orientações, os alunos, em grupos, dão início à atividade e esta se encerra somente quando há um vencedor. Portanto, sua duração pode variar.

Tempo estimado: duas horas-aula.

Apresentação expositiva dialogada: O professor, com o auxílio de um projetor para a utilização de imagens e/ou vídeos, explica aos alunos de forma mais detalhada o processo de Evolução Biológica com base nos cinco pilares da teoria evolutiva de Darwin, segundo Mayr (2005). Estes são: a evolução propriamente dita; a descendência comum; o gradualismo; a multiplicação das espécies; e a seleção natural.

Problematização: Como ocorreu a evolução e a dispersão dos mamíferos nos últimos 100 milhões de anos?

Passo 5 Os alunos são orientados pelo docente a formarem grupos e, partindo do problema sugerido, buscarem informações em livros, websites e outras ferramentas que possam ter à disposição e então desenvolverem uma narrativa descrevendo a história evolutiva dos mamíferos de maneira a abordar os cinco princípios da Evolução Biológica discutidos anteriormente. Parte dessa pesquisa pode ser desenvolvida como tarefa, uma vez que o tempo de pesquisa e compreensão das informações encontradas varia com as habilidades de cada estudante.

Tempo estimado: três horas-aula.

\section{Recapitulação e aplicação dos conteúdos aprendidos}

Avaliação individual: É solicitado aos alunos que, individualmente, elaborem um texto

Passo 6 respondendo ao primeiro questionamento feito ao início da unidade didática: Como ocorreu tamanha diversidade de seres vivos em nosso planeta?

Tempo estimado: uma hora-aula.

Quadro 1: Organização da UEPS 
De acordo com Ausubel, o fator mais importante para que uma aprendizagem significativa possa ocorrer é a interação, na estrutura cognitiva do aluno, entre o conhecimento que se pretende ensinar e algum conhecimento previamente assimilado por ele (MOREIRA, 2010). Por sua vez, Moreira (2010; 2012) justifica que quando os conhecimentos prévios dos aprendizes são insuficientes para que ocorra a aprendizagem significativa do novo conhecimento, o docente pode utilizar materiais introdutórios, chamados de organizadores prévios, a fim de fazer uma ponte entre o que o eles já sabem e o que irão aprender.

Com base nesses pressupostos defendidos por Ausubel e Moreira, a unidade didática aqui proposta apresenta os passos 1 e 2 como organizadores prévios com o objetivo de proporcionar aos aprendizes as "ideias âncoras" necessárias à aprendizagem significativa do conceito principal que se pretende ensinar, que neste caso são os princípios da Evolução Biológica, apresentados a partir do passo 3 da unidade. Além da estratégia de utilização dos organizadores prévios, destacam-se aqui dois importantes princípios programáticos facilitadores da aprendizagem significativa presentes no desenvolvimento da unidade de ensino proposta, a organização sequencial e a diferenciação progressiva. Ambos estão relacionados e são compatíveis com o atributo progressivo da aprendizagem significativa. Segundo Moreira (2010, p. 5), “[...] a aprendizagem significativa é progressiva, quer dizer, os significados vão sendo captados e internalizados progressivamente [...]".

O primeiro, a organização sequencial, tem a ver com a organização do conteúdo que se pretende ensinar e "[...] consiste em sequenciar os tópicos, ou unidades de estudo, de maneira tão coerente quanto possível com as relações de dependência naturalmente existentes entre eles na matéria de ensino" (MOREIRA, 2010, p. 6). Já o segundo, a diferenciação progressiva, postula que o que há de mais relevante na matéria de ensino seja introduzido desde o início, de modo a começar a instrução pelas ideias mais gerais e inclusivas e ir diferenciando-as progressivamente, no que se refere aos detalhes e à especificidade, no decorrer da realização da unidade de ensino (MOREIRA, 2010).

No primeiro passo, intenciona-se levar o aluno a refletir sobre a vasta variedade de seres vivos existentes no planeta Terra e questionar como teriam surgido tantas formas diferentes de vida. Entende-se, portanto, que a abordagem do tema diversidade de seres vivos aqui proposta pode desempenhar um importante papel como organizador prévio e 
DOI: https://doi.org/10.33238/ReBECEM.2021.v.5.n.1.26905

fazer a ponte entre o conhecimento prévio dos alunos e os princípios da $\mathrm{EB}$, uma vez que a percepção da pluralidade da vida é essencial para o entendimento de dois dos principais pilares da teoria evolutiva: a descendência comum e a multiplicação de espécies (MAYR, 2005).

Nesta proposta, sugere-se que o professor dê início à aula com perguntas que visem levantar os conhecimentos prévios dos alunos a respeito do conteúdo, lembrando que, de acordo com a teoria da aprendizagem significativa, são esses conhecimentos que ancorarão os novos conceitos que poderão ser aprendidos. Sendo assim, é fundamental que o educador tenha ciência do que o aprendiz já sabe sobre o conteúdo para então desenvolver as atividades planejadas buscando a interação do novo conhecimento com aquele previamente adquirido por ele. Após essa conversa inicial, o docente pode propor a primeira situação problema com o intuito de fazer com que os estudantes pensem e busquem elaborar respostas para questionamentos relacionados à dimensão da diversidade de vida, como ela ocorreu e o que conecta todas essas formas tão distintas de seres vivos. Conforme apontado por Moreira (2010, p.4), ao elaborar uma UEPS o professor deve

[...] propor situações-problema, em nível bem introdutório, levando em conta o conhecimento prévio do aluno, que preparem o terreno para a introdução do conhecimento (declarativo ou procedimental) que se pretende ensinar; estas situações-problema podem envolver, desde já, o tópico em pauta, mas não para começar a ensiná-lo; tais situações-problema podem funcionar como organizador prévio; são as situações que dão sentido aos novos conhecimentos, mas, para isso, o aluno deve percebê-las como problemas e deve ser capaz de modelá-las mentalmente; modelos mentais são funcionais para o aprendiz e resultam da percepção e de conhecimentos prévios [...] (MOREIRA, 2010, P.4).

Cabe aqui destacar a importância dos momentos em que o docente faz questionamentos ou propõe situações-problema aos estudantes, pois nestes há o estímulo à reflexão e à participação ativa nos processos de ensino e aprendizagem, buscando, assim, uma aprendizagem não somente significativa, mas também crítica (MOREIRA, 2010; FREIRE; 2018).

Após este primeiro momento, recomenda-se nesta UEPS o uso do vídeo "Bio é vida - A diversidade de seres vivos" e da imagem de uma árvore filogenética, ambos como apoio à exposição oral do docente cuja finalidade é contribuir para a compreensão, por parte dos alunos, da diversidade de seres vivos existentes em nosso planeta. Este entendimento, por sua vez, auxiliará na construção de organizadores prévios ao aprendizado das ideias evolucionistas que serão mais tarde apresentadas. É neste 
DOI: https://doi.org/10.33238/ReBECEM.2021.v.5.n.1.26905

momento, também, que o professor terá a oportunidade de colocar em ação outro princípio relevante para que ocorra a aprendizagem significativa: a negociação de significados. Este princípio diz respeito à troca de significados entre o professor e o aluno e é o momento ideal para que o docente se certifique de que os estudantes captaram os significados de forma correta levando em consideração o contexto da matéria de ensino. Segundo Moreira (2010), respaldado pelas ideias de Bob Gowin, a interação entre educando e educador é fundamental para que haja aprendizagem significativa, pois “[...] um episódio de ensino se consuma quando aluno e professor compartilham significados sobre os materiais educativos do currículo" (p. 13). No entanto, este compartilhamento de significados não deve ser feito somente por meio de respostas, mas preferencialmente mediante uma constante troca de perguntas, ou seja, da elaboração e busca pela resolução de situações-problema (MOREIRA, 2010).

Para o segundo passo, o conteúdo proposto é o tempo cósmico (ou geológico), que na unidade apresentada também tem a função de organizador prévio, pois, juntamente com a noção da diversidade dos seres vivos apresentada anteriormente, fornece conceitos capazes de fundamentar e ancorar o conhecimento mais complexo e específico que se almeja ser aprendido pelos alunos no decorrer da UEPS (MOREIRA, 2010). A compreensão do tempo cósmico por parte dos estudantes é fundamental para a aprendizagem de conceitos mais específicos e que integram a teoria da Evolução Biológica proposta por Darwin, como a descendência comum, a multiplicação de espécies e o gradualismo (MAYR, 2005). Desta forma, a organização dos conteúdos apresentada na unidade de ensino mais uma vez respeita o princípio da diferenciação progressiva, que defende "[...] que ideias, conceitos, proposições mais gerais e inclusivos do conteúdo devem ser apresentados no início do ensino e, progressivamente, diferenciados, ao longo do processo, em termos de detalhes e especificidades" (MOREIRA, 2012, p. 9).

O passo 2, assim como o primeiro, começa com questionamentos que visam identificar o que os estudantes já sabem sobre o tema, pois assim o professor pode desenvolver sua aula tendo como base esses conhecimentos prévios. Ainda antes da apresentação do conhecimento que aqui pretende-se ensinar, recomenda-se que o docente relembre, juntamente com os estudantes, o que foi discutido nas aulas anteriores uma vez que os temas dos passos iniciais, a diversidade de seres vivos e o tempo cósmico, possuem uma estreita relação que precisa ser compreendida pelos estudantes para que seja possível a aprendizagem significativa dos próximos passos. Além disso, esta recapitulação é pertinente neste momento porque pode favorecer a negociação de significados, a 
DOI: https://doi.org/10.33238/ReBECEM.2021.v.5.n.1.26905

diferenciação progressiva e a reconciliação integradora no transcorrer das aulas (MOREIRA, 2010). Este último quer dizer que além da progressiva diferenciação do conteúdo, cuja relevância já foi anteriormente destacada, deve-se “[...] também explorar, explicitamente, relações entre conceitos e proposições, chamar a atenção para diferenças e semelhanças e reconciliar inconsistências reais e aparentes" (MOREIRA, 2010, p.5) no andamento da UEPS a fim de que se possibilite aos discentes uma aprendizagem significativa. A este princípio, portanto, é dado o nome de reconciliação integradora (MOREIRA, 2010).

No momento seguinte, introduz-se o conceito de tempo cósmico como uma importante variável para a compreensão da diversificação das formas de vida existentes e, relembrando as perguntas iniciais, pode-se traçar uma linha do tempo resumida, de modo a destacar os principais eventos envolvendo a formação do cosmos e o surgimento da vida. Após esta explanação, sugere-se ao educador que utilize o Calendário Cósmico (https://upload.wikimedia.org/wikipedia/commons/9/99/Cosmic_Calendar.png), idealizado pelo cientista e escritor Carl Sagan, com a finalidade de facilitar o entendimento dos estudantes em relação à proporção do tempo cósmico. Nesta ocasião, o vídeo apresentado pelo cientista Neil deGrasse Tyson, no qual ele demonstra o calendário criado por Sagan, pode ser utilizado como uma ferramenta para introduzir o assunto e dar suporte à atividade a ser proposta. Esta atividade consiste na elaboração de calendários cósmicos pelos estudantes e tem como função ser a segunda situaçãoproblema sugestionada nesta unidade de ensino. Ela, portanto, tem por objetivo estimular que os educandos investiguem e construam o próprio conhecimento, valendo-se de alguns dos conceitos assimilados, por meio da criação, preferencialmente em grupos, de seus próprios calendários cósmicos nos quais devem evidenciar os principais eventos ocorridos ao longo da história do nosso Planeta que sejam relacionados ao surgimento e à diversificação das formas de vida na Terra.

O passo 3 da UEPS é o momento em que o professor começa a ensinar aos aprendizes o conhecimento a ser aprendido após ser precedido por conteúdos e situações cuja função pretendida é a de organizador prévio, ou seja, com o objetivo de fazer uma "ponte" entre o que o aluno já sabe e aquilo que necessita aprender sobre determinado tema. Neste caso, os princípios da Evolução Biológica.

Ao introduzir um novo tema, o educador inicia esta etapa da mesma maneira que iniciou as anteriores, procurando identificar os conhecimentos prévios dos alunos por meio de perguntas e discussões propostas em sala. Após ouvir e debater com os alunos 
DOI: https://doi.org/10.33238/ReBECEM.2021.v.5.n.1.26905

sobre suas concepções a respeito da EB, indica-se ao professor que exiba aos estudantes o vídeo "Nós, os fantásticos seres vivos: uma breve história sobre Evolução" com o propósito de ilustrar alguns conceitos e fundamentá-los com determinadas informações e ideias que podem facilitar o entendimento e enriquecer as discussões sobre o assunto (MOREIRA, 2010). Após a retomada das discussões, realizada ao final do vídeo como orientado na unidade didática, o docente deve relembrar os educandos dos questionamentos realizados previamente, aproveitando para adicionar uma importante questão a ser trabalhada e posteriormente respondida por eles: "Há relação entre a Evolução Biológica e a diversidade de seres vivos encontrada no planeta Terra? Se sim, qual?”. O intuito aqui é promover uma reflexão acerca da relação entre a diversidade de seres vivos e a EB. A questão é proposta como mais uma situação-problema a ser solucionada pelos estudantes, lembrando que "são as situações que dão sentido aos conceitos, mas à medida que o sujeito vai construindo conceitos mais capaz ele fica de dar conta de novas situações, cada vez mais complexas” (MOREIRA, 2012, p. 11).

Durante este passo, é essencial que o docente desenvolva as atividades propostas buscando estar em consonância com os principais princípios e estratégias facilitadores da aprendizagem significativa. Além da organização sequencial e diferenciação progressiva, já consideradas na concepção da UEPS, recomenda-se ao educador que procure realizar a negociação de significados e a reconciliação integradora no decorrer de suas ações. Estas duas estratégias têm papel fundamental nesta fase, pois é neste momento que o professor deve se certificar que as atividades anteriores, utilizadas como organizadores prévios, estão fazendo sentido para os estudantes e funcionando como ancoradouro para que haja a aprendizagem significativa do conteúdo apresentado. Lembrando que, para que isso de fato aconteça, a matéria de ensino precisa ser assimilada de forma não-literal e não-arbitrária pelos alunos (MOREIRA, 2010).

Não menos importante, a partir desta fase da UEPS mais um princípio facilitador da aprendizagem significativa precisa ser levado em conta: a consolidação do conhecimento. De acordo com Moreira (2010, p. 9), “[...] é preciso insistir no domínio ou mestria do que está sendo estudado, antes que novos materiais sejam introduzidos, buscando assegurar contínua prontidão na matéria de ensino e sucesso na aprendizagem sequencialmente organizada", ou seja, para que a aprendizagem de um conhecimento seja efetiva, é necessário consolidar os conceitos previamente ensinados antes que novos conceitos sejam apresentados.

Diante disso, o quarto passo é uma atividade prática, um jogo intitulado “Jogo da 
DOI: https://doi.org/10.33238/ReBECEM.2021.v.5.n.1.26905

Evolução". Segundo Mayra Galvão et al. (2012, p. 67), o “[...] objetivo ao apresentar o "Jogo da Evolução" é o de facilitar a visualização dos efeitos de diferentes mecanismos evolutivos nas populações, além de promover a discussão e de reforçar a compreensão de conceitos [...]" relacionados à Evolução Biológica de uma forma diferente, divertida e lúdica, fugindo do modelo tradicional de ensino. Sugere-se que esta atividade seja trabalhada como mais uma situação-problema. Durante a prática do jogo o educador tem a oportunidade de mais uma vez negociar significados com os aprendizes, realizar a reconciliação integradora e promover a consolidação dos conceitos apresentados na etapa anterior antes de seguir para a apresentação de novos conceitos, programados para serem trabalhados no próximo passo desta unidade de ensino. Aqui, então, retoma-se o conteúdo do passo 3, porém em nível crescente de complexidade de forma que possa desafiar os alunos a utilizarem os conceitos aprendidos em novas e diversificadas situações-problema (MOREIRA, 2012).

Para a realização da atividade, recomenda-se que os estudantes sejam separados em grupos e que o professor seja um mediador, auxiliando os alunos com dificuldades que possam surgir. De acordo com Galvão et al. (2012), esta atividade pode ser trabalhada tanto com o ensino fundamental quanto com o ensino médio, pois não requer um conhecimento aprofundado sobre Evolução. Este fato vai ao encontro dos objetivos desta UEPS, visto que ela é pensada para estudantes do primeiro ano do ensino médio e se propõe também a ensinar os princípios da Evolução Biológica. O jogo envolve importantes conceitos ligados aos princípios da EB, como a variedade de fenótipos dentro de uma população, o papel do acaso e a seleção natural e sexual. Nele, cada aluno (ou grupo) é representado por um indivíduo de uma população e ganha a partida aquele que chegar ao final com mais filhotes vivos, ou seja, aquele que deixar mais descendentes para a próxima geração (GALVÃO et al., 2012).

No passo 5, seguindo o pressuposto da diferenciação progressiva, os princípios da $\mathrm{EB}$, que aqui representa o conhecimento que se pretende ser ensinado/aprendido, devem ser apresentados pelo docente em nível mais alto de complexidade e especificidade (MOREIRA, 2012). Nesta etapa, portanto, recomenda-se o uso da aula expositiva dialogada como estratégica didática. Nela, o professor tem a oportunidade de esclarecer as cinco ideias darwinistas da Evolução, consideradas a base para o entendimento do fenômeno evolutivo. São elas: a evolução propriamente dita, explicada como um fato observável, pois o mundo e tudo que há nele está em constante transformação; a descendência comum, ou seja, o entendimento de que todas as formas de vida do planeta 
DOI: https://doi.org/10.33238/ReBECEM.2021.v.5.n.1.26905

são aparentadas e descendem de um único ancestral; o gradualismo, teoria defendida por Darwin de que a evolução é o acúmulo lento e gradual das alterações ocorridas em populações de organismo; a multiplicação de espécies, isto é, por causa do acúmulo de mudanças em populações, uma espécie ancestral pode dar origem a uma ou mais espécies diferentes; e a seleção natural, definida por seus dois princípios fundamentais, a produção de variação que é natural aos organismos vivos e a discriminação das características por seleção ou eliminação (MAYR, 2005).

A abordagem adotada pelo educador durante a explanação deve compreender momentos de discussão, nos quais os aprendizes tenham abertura para se manifestarem e externalizarem os significados captados, favorecendo assim a troca, ou negociação, de significados que é tão importante para que ocorra a aprendizagem significativa e crítica. Além disso, orienta-se ao docente que revisite os temas previamente trabalhados, utilizando-se de novos exemplos e situações, de modo a identificar relações, semelhanças e diferenças, buscando, assim, a reconciliação integradora no decorrer do processo pedagógico (MOREIRA, 2010; 2012).

Após a exposição e a discussão dos conceitos propostos, os educandos são orientados a realizar uma atividade em grupos com a finalidade de solucionar mais uma situação-problema posta pelo educador, esta em nível mais alto de complexidade do que as anteriores (MOREIRA, 2012). Assim, os estudantes são incentivados a buscar informações em livros e documentos, físicos ou virtuais, sobre a história evolutiva e dispersão dos mamíferos nos últimos cem milhões de anos. Em seguida, eles devem elaborar uma narrativa descrevendo os principais acontecimentos de forma a identificar e destacar os cinco princípios da teoria evolutiva darwinista aprendidos anteriormente. Com esta atividade, busca-se uma participação ativa dos alunos na construção do conhecimento e a capacitação destes para o reconhecimento do fenômeno evolutivo como processo intrínseco à diversidade de seres vivos (MAYR, 2005; 2009).

Segundo Moreira (2012), a avaliação da aprendizagem deve ser formativa e ocorrer ao longo de toda a implementação da UEPS. Seguindo este princípio, propõe-se neste estudo que o professor avalie a aprendizagem dos alunos no decorrer de cada passo da UEPS, levando em conta a participação deles nas discussões e nas atividades desenvolvidas. $\mathrm{O}$ autor também sugere que, ao final da unidade, seja realizada uma avaliação somativa individual "[...] na qual deverão ser propostas questões/situações que impliquem compreensão, que evidenciem captação de significados e, idealmente, alguma capacidade de transferência" (MOREIRA, 2012, p. 4). 
DOI: https://doi.org/10.33238/ReBECEM.2021.v.5.n.1.26905

Portanto, o sexto e último passo desta UEPS é dedicado à avaliação final e individual da aprendizagem significativa, por parte dos aprendizes, dos conceitos e fenômenos que se pretendeu ensinar nos passos anteriores. Orienta-se ao docente que retome a questão inicialmente estabelecida - "Como ocorreu tamanha diversidade de seres vivos em nosso planeta?" - e solicite aos estudantes que a respondam mediante a elaboração de um texto, de uma apresentação oral, da produção de um vídeo ou de qualquer outra forma de comunicação que o educador julgar pertinente. Espera-se que, tendo ocorrido a aprendizagem significativa dos princípios evolutivos darwinianos, os educandos sejam capazes de compreender o advento e o avanço da diversidade das formas de vida sob a perspectiva do pensamento evolutivo, bem como perceber os demais fenômenos e mecanismos biológicos tendo a EB como eixo integrador.

Além dos princípios facilitadores da aprendizagem significativa, destacados nas etapas da UEPS, a construção desta unidade também teve como base alguns princípios, ideias e estratégias estabelecidos por Moreira (2010) cuja finalidade é a de favorecer uma aprendizagem que seja não somente significativa, mas sobretudo crítica. Os principais princípios aqui seguidos, que permeiam todo o desenvolvimento da unidade de ensino e que devem guiar as ações dos educadores que desejarem utilizá-la em sala de aula, são os seguintes:

- A ideia de que aprendemos principalmente a partir do que já sabemos;

- A importância de se ensinar por meio de questionamentos e não de respostas prontas;

- A utilização de materiais diversificados e a não centralização do livro didático;

- A ideia de que o aprendiz é um agente perceptor e representador do mundo e não apenas um receptor passivo de ideias prontas;

- A concepção do erro como algo natural e parte do aprendizado;

- A estratégia da desaprendizagem, ou seja, da não utilização de determinados conhecimentos prévios que estejam em desacordo com os conceitos a serem aprendidos;

- O conhecimento como construção humana e não como verdade absoluta;

- O uso de estratégias diversificadas de ensino nas quais o aluno participe ativamente na construção do conhecimento;

- O princípio de que o estudante é o ator principal no processo de ensino e 
DOI: https://doi.org/10.33238/ReBECEM.2021.v.5.n.1.26905 aprendizagem e que, portanto, precisa ser ouvido. No ensino centrado no aluno o professor tem papel de mediador e deve procurar sempre estimular o envolvimento e a comunicação com os estudantes, evitando o modelo de ensino por narrativa. De acordo com este último princípio, mais importante do que aprender conceitos prontos é "aprender a aprender" (MOREIRA, 2010).

Segundo Araújo (2017, p. 24), “[...] uma compreensão crítica da evolução exerce um importante papel na educação para o exercício da cidadania, sobretudo na tomada de decisões frente a dilemas sociocientíficos". Ainda de acordo com o autor, essa compreensão se torna mais ampla quando relacionada às noções da extensão do tempo em que a vida vem evoluindo e da dimensão da diversidade de seres vivos que resultam deste processo. Isso permite, entre outras coisas, o entendimento de que o ser humano é parte da natureza, fazendo com que o pensamento evolutivo tenha, também, implicação em questões de ordem cultural e existencial, inerentes à humanidade (ARAÚJO, 2017).

\section{Considerações finais}

Este estudo se propôs a conceber e estruturar uma unidade de ensino com a potencialidade de promover a aprendizagem significativa e crítica dos princípios fundamentais para a construção de um pensamento evolutivo por parte dos estudantes. Este pensamento evolutivo, por sua vez, é essencial para que haja uma efetiva compreensão dos conceitos e fenômenos ensinados na disciplina de Biologia ao longo do Ensino Médio, visto que é a Evolução Biológica que unifica e dá sentido à Biologia (MEYER; EL-HANI, 2005; MAYR, 2005).

No decurso da pesquisa decidiu-se que a maneira mais adequada para se resolver o problema proposto seria estruturar uma unidade didática no formato de Unidade de Ensino Potencialmente Significativa (UEPS), pensada e organizada por Moreira (2012). O motivo desta escolha foi o fato de que as UEPS são concebidas com base nos princípios da Aprendizagem Significativa Crítica e proporcionam a estruturação das ações de ensino de modo integrador. Foi também sob orientação do propósito do trabalho que se chegou ao entendimento de que a unidade a ser construída deveria ser pensada para o início do primeiro ano do Ensino Médio (EM), para que os estudantes potencialmente compreendam os eventos e processos das Ciências Biológicas de maneira integrada e 
DOI: https://doi.org/10.33238/ReBECEM.2021.v.5.n.1.26905

contextualizada ao longo de todo o EM.

É fundamental que esta UEPS seja entendida como um ponto de partida, como subsunçores, para a construção de uma concepção evolucionista da Biologia. Isso significa que as ideias apresentadas e discutidas nesta unidade precisam ser revisitadas, reforçadas e correlacionadas aos diversos conceitos e fenômenos biológicos abordados no decorrer do ensino da disciplina no EM. Ou seja, é preciso que o professor assuma a Evolução como eixo integrador em suas aulas ao longo de todo o Ensino de Biologia. Além disso, a unidade de ensino proposta não ambiciona esgotar o conteúdo de EB, devendo este ser novamente tratado, porém em níveis crescentes de complexidade e especificidade, conforme o desenvolvimento da disciplina. Alguns exemplos são a Evolução Humana e a relação entre EB e Genética, comumente trabalhados no último ano do Ensino Médio.

É importante esclarecer que não se pretende, com este trabalho, estipular uma única ou definitiva solução para o ensino de Evolução Biológica. Há, certamente, outras maneiras pelas quais o fenômeno evolutivo pode ser aprendido de modo a exercer o papel de eixo integrador do Ensino de Biologia, porém espera-se que esta UEPS, construída e analisada com base na articulação teórica de contribuições da Didática da Biologia, da Aprendizagem Significativa Crítica e da Epistemologia da Biologia, seja uma ferramenta eficaz para esta finalidade.

\section{Referências}

ARAÚJO, L. A. L. Evolução biológica: da pesquisa ao ensino. Porto Alegre: Editora Fi, 2017.

BRASIL. Ministério da Educação. Base Nacional Comum Curricular: ensino médio. 2017. Disponível em:

$<$ http://portal.mec.gov.br/index.php?option=com_docman\&view $=$ download \&alias=85121bncc-ensino-medio\&category_slug=abril-2018-pdf\&Itemid=30192>. Acesso em: 15 mar. 2020.

DOBZHANSKY, T. Nothing in Biology Makes Sense Except in the Light of Evolution. American Biology Teacher, Washington D. C., v. 35, n. 3, p. 125-129, Mar., 1973.

FONSECA, J. J. S. Metodologia da pesquisa Científica. Fortaleza: UEC, 2002. Apostila. Disponível em: 
DOI: https://doi.org/10.33238/ReBECEM.2021.v.5.n.1.26905

$<\mathrm{https}$ ://books.google.com.br/books?id=oB5x2SChpSEC\&printsec=frontcover\#v=onepage \&q\& $\mathrm{f}=$ false $>$. Acesso em 14 de abril de 2021.

FREIRE, P. Pedagogia da Autonomia. 56ª ed. Rio de Janeiro/São Paulo: Paz \& Terra, 2018.

GALVÃO, M. F.; BASTOS, R. W.; MOREIRA, F. F.; RODRIGUES, A. C.; YOTOKO, K. C. Jogo da Evolução. Genética na Escola. Viçosa: Universidade Federal de Viçosa, v. 7, n. 2, p. 66-73, 2012.

GIL, A.C. Como elaborar projetos de pesquisa. $4^{\mathrm{a}}$ ed. São Paulo: Atlas, 2008.

MAYR, E. Biologia, ciência única: reflexões sobre a autonomia de uma disciplina científica. $1^{\mathrm{a}}$ ed. São Paulo: Companhia das Letras, 2005.

MAYR, E. O que é a evolução. $1^{\text {a }}$ ed. Rio de Janeiro: Rocco, 2009.

MEYER, D.; EL-HANI, C. N. Evolução: o sentido da biologia. São Paulo: Editora UNESP. 2005.

MOREIRA, M. A. Unidades de Ensino Potencialmente Significativas - UEPS. Porto Alegre, 2012. Disponível em: <http://www.if.ufrgs.br/ moreira/>. Acesso em: 10 jul. 2019.

MOREIRA, M. A. Aprendizagem Significativa Crítica. 2a ed. Porto Alegre, 2010. Disponível em: < http://moreira.if.ufrgs.br>. Acesso em: 05 jul. 2019.

OLEQUES, L. C.; BOER, N.; TEMP, D. S.; BARTHOLOMEI-SANTOS, M. L. Evolução biológica como eixo integrador no ensino de biologia: concepções e práticas de professores do ensino médio. In: Encontro Nacional de Pesquisa em Educação em Ciências, 8, 2011, Campinas. Anais... Campinas: ABRAPEC, 2011. p. 01-12 Disponível em:

<http://abrapecnet.org.br/atas_enpec/viiienpec/resumos/R1066-1.pdf〉. Acesso em: 15 jul. 2019.

PARANÁ. Secretaria de Estado da Educação do Paraná. Diretrizes Curriculares da Educação Básica. Curitiba: 2008.

PARANÁ. Referencial Curricular do Paraná: princípios, direitos e orientações. Curitiba, 2018. Disponível em:

<http://www.educadores.diaadia.pr.gov.br/arquivos/File/bncc/2018/referencial_curricular_paran a_cee.pdf >. Acesso em: 16 nov. 2020.

TIDON, R.; LEWONTIN, R. C. Teaching evolutionary biology. Genetics and Molecular Biology, v.27, n.1, p.124-31, Mar., 2004. 
DOI: https://doi.org/10.33238/ReBECEM.2021.v.5.n.1.26905

ZAMBERLAN, S. J.; SILVA, M. R. O Ensino de Evolução Biológica e sua Abordagem em Livros Didáticos. Educação \& Realidade, Porto Alegre, v. 37, n. 1, p. 187-212, abr., 2012.

Recebido em: 06 de fevereiro de 2021

Aceito em: 12 de abril de 2021 